\title{
ANALISIS PENINGKATAN KANDUNGAN KOMPONEN LOKAL PADA PEMBANGUNAN KAPAL BARU DI DALAM NEGERI
}

\author{
Improvement Analysis of Component Local Content on Domestic New Building \\ Taufik Hidayat ${ }^{1}$, dan Buana Ma'ruf ${ }^{2}$ \\ ${ }^{1}$ Naval Architecture Departement, Institut Teknologi Kalimantan, Balikpapan. \\ ${ }^{2}$ Agency for Assessment and Aplication of Technology, BTH-Surabaya. \\ E-mail: taufikhidayat.expert@gmail.com
}

Diterima: 13 Januari 2016; Direvisi: 4 Nopember 2016; Disetujui: 22 Nopember 2016

\begin{abstract}
Abstrak
Dalam 20 tahun terakhir industri galangan kapal berkembang sangat lambat. Hal ini dipengaruhi oleh ketersediaan industri komponen lokal. Rendahnya tingkat komponen dalam negeri (TKDN) menyebabkan industri galangan kapal nasional tidak berdaya saing. Daya saing tersebut dipengaruhi oleh daya saing industri dan daya saing nasional, sehingga permasalahan industri galangan kapal harus dipecahkan secara komprehensif, disertai langkah-langkah strategik dan sistematis agar dapat bersaing secara berkesinambungan. Industri galangan kapal terkemuka menjadikan pengembangan industri komponen lokal sebagai pilar bagi perekonomian negaranya. Pengembangan industri komponen lokal yang terintegrasi mempunyai peran yang penting dalam pengembangan industri galangan kapal. Paper ini menganalisis TKDN komponen dan potensi peningkatannya pada pembangunan kapal baru di dalam negeri. Kategori komponen yang digunakan sesuai dengan BKI. Studi kasus dilakukan pada Kapal Tanker 17500 LDWT buatan PT. PAL tahun 2012 dan Kapal Perintis 750 DWT buatan PT. ASSI tahun 2015. Hasil yang diperoleh menunjukan bahwa penerapan stategi product development yang bertujuan untuk market penetration secara backward integration dapat meningkatkan potensi TKDN pada pembangunan kapal baru. Potensi TKDN yang didapat pada kasus Kapal Tanker 17500 LDWT adalah sebesar 21.98 persen, sedangkan pada kasus Kapal Perintis 750 DWT adalah sebesar 8.22 persen.
\end{abstract}

Kata kunci : komponen kapal, strategi daya saing, tingkat kandungan dalam negeri

\begin{abstract}
In the last 20 years the shipbuilding industry has been growing very slowly. It is affected by the availability of local component industry. Low levels of domestic components causing national shipbuilding industry is not competitive. The competitiveness of the national shipbuilding industry is affected by industrial competitiveness and national competitiveness, so that the problems of the shipbuilding industry should be solved in a comprehensive manner, accompanied by measures for strategic and systematic in order to compete sustainably. Leading shipbuilding industry makes the development of the local component industry as a pillar for the economy of the country. The development of integrated local components industry has an important role in the development of shipbuilding industry. This paper analyzes TKDN components and the potential increase in the construction of new vessels in the country. Categories of components used in accordance with BKI. The case studies carried out on the tanker 17500 LDWT made by PT. PAL in 2012 and Perintis 750 DWT ships made by PT. ASSI 2015. The results obtained show that the application of the product development that aims for market penetration by backward integration strategy may increase the potential for local content on the construction of new vessels. Potential TKDN obtained in the case of tanker 17500 LDWT up to 21.98 per cent, whereas in the case of Perintis 750 DWT up to 8.22 percent.
\end{abstract}

Keyword : ship components, competitiveness strategy, local content level 


\section{PENDAHULUAN}

Industri galangan kapal di Indonesia belum sukses dan cenderung tidak terarah, seperti tidak memiliki strategi (Ma'ruf, 2014). Menurutnya produktivitas dan mutu yang rendah, serta harga yang lebih tinggi menyebabkan industri galangan kapal nasional tidak berdaya saing. Mutu dan waktu berkaitan dengan fasilitas dan peralatan yang konvensional, serta perencaan yang lemah. Sedangkan harga terkait dengan material dan komponen, dimana mayoritas masih impor dengan harga 70 hingga 80 persen lebih mahal dibandingkan lokal. Jika dibandingkan dengan industri galangan kapal terkemuka di dunia, mereka mempunyai tingkat komponen lokal yang tinggi (China 70 persen, Korea Selatan 90 persen, Jepang 98 persen, dan Vietnam 70 persen), karena pengembangan industri material dan komponen lokal menjadi prioritas utama dan sebagai pilar bagi perekonomian negaranya (Hidayat dan Ma'ruf, 2015).

Industri galangan kapal merupakan industri yang bersaing secara global dan dipengaruhi secara makro, karena itu pemerintah mempunyai peran yang penting (Ma'ruf, 2014). Kementerian Perindustrian (Kemenperin) telah mengusulkan penghapusan pajak pertambahan nilai (PPn) untuk pembelian komponen dalam negeri oleh pengusaha perkapalan. Kebijakan ini dibuat sebagai insentif kepada pelaku usaha perkapalan di tanah air agar industri komponen dalam negri bisa maju, karena Kemenperin menargetkan industri komponen harus dapat membuat industri perkapalan nasional mendunia. Untuk itu pemerintah telah mewajibkan penggunaan produk dengan Tingkat Kandungan Dalam Negeri (TKDN) mencapai 40 persen.

Visi program "Tol Laut" dan maritim untuk lima tahun ke depan adalah momentum untuk pengembangan industri galangan kapal nasional. Namun meskipun pemerintah akan memberikan insentif seperti bea masuk pembelian komponen dan tunjangan pajak pada komponen impor, industri galangan kapal di Indonesia, tetap tidak akan mencapai target (Wee, 2013). Rendahnya tingkat produktivitas dan kapasitas menyebabkan industri galangan kapal nasional tidak berdaya saing. Daya saing industri adalah faktor yang menentukan keberhasilan atau kegagalan suatu industri. Menurut Ma'ruf (2014), daya saing industri galangan kapal nasional dipengaruhi oleh daya saing industri dan daya saing nasional, sehingga permasalahan industri galangan kapal harus dipecahkan secara komprehensif, disertai langkah-langkah strategik dan sistematis agar dapat bersaing secara berkesinambungan.

\section{TINJAUAN PUSTAKA}

Pengembangan industri komponen lokal yang terintegrasi mempunyai peran yang penting dalam pengembangan industri galangan kapal (Hidayat dan Ma'ruf, 2015). Sebagian besar industri galangan kapal terkemuka di dunia, menerapkan strategi korporasi dan bisnis untuk membuat industri galangan kapalnya mempunyai daya saing yang berkelanjutan. Mereka meningkatkan TKDN-nya dengan kombinasi dari strategi backward integration, market penetration, dan product development. Backward integration (Gambar 1) adalah aliansi dengan pemasok kebutuhan dasar pokok (bahan baku, jasa, komponen, dll) yang bertujuan untuk menjaga kelancaran suplai dan mendapatkan nilai ekonomis. Market penetration adalah meningkatkan pangsa pasar terhadap produk pada pasar yang dimiliki (domestik), melalui pemasaran yang lebih agresif. Strategi ini bertujuan untuk mendapatkan skala ekonomi jangka panjang dan profit margin yang optimal. Product development adalah meningkatkan penjualan melalui pengembangan pada produk yang sudah ada atau baru. Inovasi pada produk harus mampu memberikan differensiasi dan nilai tambah kepada pelanggan serta masih sesuai dengan kompetensi inti. Untuk dapat menguasai pasar domestik, dibutuhkan ketersediaan industri bahan baku, jasa, dan komponen lokal. Nilai tambah pada produk dibutuhkan untuk memberikan differensiasi.

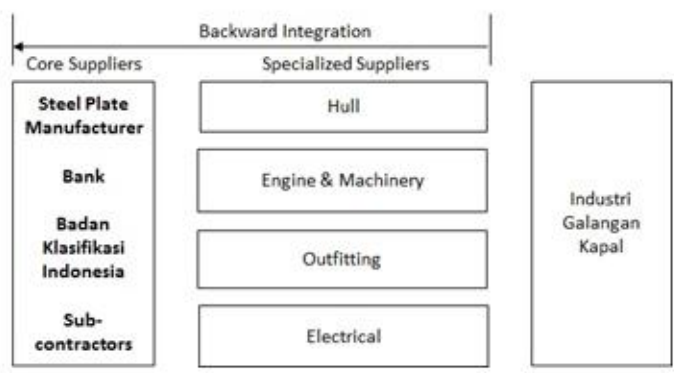

Gambar 1. Backward integration

Pengembangan industri bahan baku (seperti pelat, kawat las, dll.) dan jasa (sub-kon, bank, dll.) serta komponen adalah sebagai langkah penetrasi pasar (market penetration) lainnya. Sehingga pasar domestik 


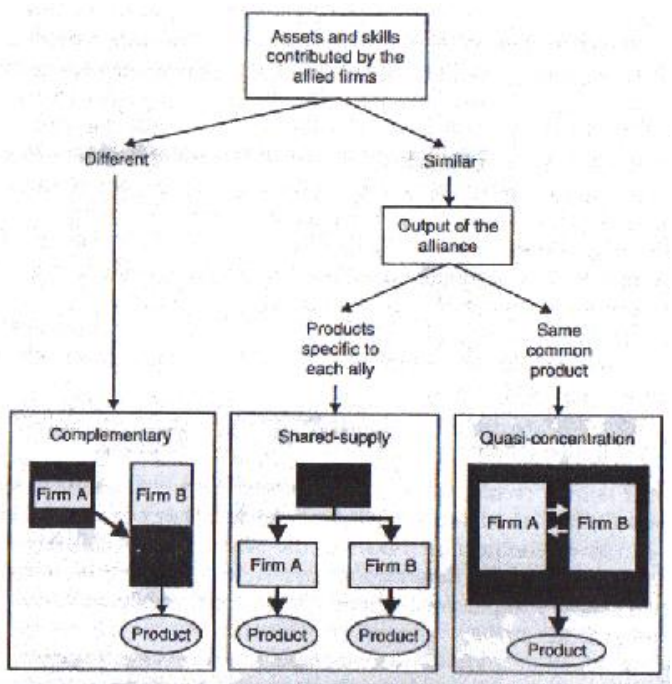

Gambar 2. Tiga tipe aliansi antara kompetitor (Dussauge dan Garrette, 1999)

dapat dikuasai oleh produk dalam negeri, memperbanyak lapangan kerja, dan mengurangi dana yang pergi keluar negeri juga menambah nilai ekonomis, karena tersedia secara lokal/dekat. Strategi yang dilakukan di Jepang adalah standarisasi komponen (product development), seperti obat generik. Satu resep, berbagai macam merk, produk dan namanya sama. China pun menerapkan hal yang sama pada beberapa produk komponennya, seperti safety equipment yang marine-use. Sehingga standarisasi komponen adalah komponen yang mempunyai ukuran, bahan, dan klasifikasi yang sama. Sehingga nantinya hanya produsen/industri komponennya (merek) yang berbeda.

Tidak semua industri memiliki fasilitas dan peralatan yang lengkap. Apalagi industri yang baru akan dikembangkan. Investasi sebuah fasilitas atau peralatan tidaklah murah dan membutuhkan waktu pengembalian modal yang cukup lama. Solusinya adalah penerapan aliansi antara kompetitor. Terdapat tiga aliansi antara kompetitor, yaitu complementary, shared-supply, dan quasi-concentration (Gambar 2). Aliansi shared-supply adalah aliansi yang dilakukan perusahaan mencapai skala ekonomi pada komponen tertentu atau pada tahap individu dalam proses produksi. Aliansi quasi-concentration adalah aliansi yang dilakukan perusahaan yang mengembangkan, memproduksi, dan memasarkan produk bersama. Sehingga aliansi ini umumnya meliputi semua fungsi utama yang termasuk dalam semua aktivitas, R\&D, proses manufaktur, dan pemasaran. Aliansi complementary adalah aliansi yang dilakukan perusahaan yang berkontribusi pada aset dan keterampilan dari sifat yang berbeda untuk proyek kolaboratif.

Menurut BKI (Badan Klasifikasi Indonesia), komponen kapal dikategorikan menjadi lima, yaitu hull construction, hull outfitting, machinery outfitting, electrical outfitting dan accomodation. Menurut kajian dari Hidayat dan Ma'ruf (2015) memang secara umum, komponen kapal dikategorikan menjadi hull construction (HC) termasuk painting, hull outfitting (HO), machinery outfitting (MO), electrical outfitting (EO), dan Accomodation. Kategori adalah kelas atau divisi dari sesuatu atau hal yang dianggap memiliki karakteristik tertentu yang sama. Kategori digunakan pada sesuatu yang over populated, sehingga lebih mudah untuk diatur.

Industri komponen disebut specialized supplier, karena memiliki produk yang terspesialisasi. Sedangkan industri bahan baku dan jasa disebut core supplier, karena merupakan inti/bahan dasar.

Studi kasus untuk analisis peningkatan kandungan komponen lokal ini menggunakan Kapal Tanker 17500 LDWT (PAL, 2012) dan Kapal Perintis 750 DWT (ASSI, 2015). Persentase bobot harga pada tiap kapal ditunjukan oleh Tabel 1 dan Tabel 2.

\section{METODE PENELITIAN}

Penelitian ini dilaksanakan dengan pendekatan kajian pustaka dan studi kasus. Kajian pustaka mencakup kajian kategori komponen kapal menurut BKI, data komponen kapal dan data impor komponen, serta referensi terkait. Data dan informasi ini diperoleh melalui pengumpulan data primer dan sekunder serta diskusi.

Data komponen diolah untuk didapatkan bobot harganya. Kemudian data tersebut diolah kembali dengan menggabungkan data impor komponen. Hasil yang didapatkan adalah komponen-komponen apa saja yang sudah menggunakan produk lokal dan masih menggunakan produk impor. Komponen yang masih impor dianalisis potensinya, dan diasumsikan dengan aliansi antar kompetitor serta product development sehingga dapat dikembangkan di dalam negeri. Hasil dari analisis peningkatan kandungan komponen lokal adalah berdasarkan komponen berpotensi yang diasumsikan dapat dikembangkan di dalam negeri. 


\section{HASIL DAN PEMBAHASAN Identifikasi TKDN}

Studi kasus pada paper ini menggunakan asumsi bahwa bobot cost dari tiap kategori merupakan hasil persentase kapal. Persentase ini diolah dengan data komponen lokal sehingga didapatkan dasar persentase TKDN.

Tabel 1. Bobot harga pada Kapal Tanker 17500 LDWT (PAL, 2012; diolah)

\begin{tabular}{lr}
\hline \multicolumn{1}{c}{ Kategori } & \multicolumn{1}{c}{ Bobot } \\
\hline HC + Paint & $29.91 \%$ \\
\hline HO & $25.12 \%$ \\
\hline MO & $29.50 \%$ \\
\hline EO & $10.12 \%$ \\
\hline Acc & $5.35 \%$ \\
\hline Total & $100.00 \%$ \\
\hline
\end{tabular}

Pada kasus pertama (Tabel 1) yaitu pada Kapal Tanker 17500 LDWT didapatkan persentase bobot, yaitu hull construction (HC, termasuk paint) 29.91 persen, hull outfitting (HO) 25.12 persen, machinery outfitting (MO) 29.50 persen, electrical outfitting (EO) 10.12 persen, dan accomodation (Acc) 5.35 persen. Data yang diolah adalah penggabungan persentase bobot harga (PAL, 2012; diolah) dengan data ekspor impor komponen (PAL, 2015), serta diskusi dan informasi pendukung lainnya. Sehingga didapatkan bobot persentase TKDN pada komponen sebesar 34.95 persen, sedangkan sisanya adalah komponen impor sebesar 65.05 persen.

Tabel 2. Bobot harga pada Kapal Perintis 750 DWT (ASSI, 2015; diolah)

\begin{tabular}{lr}
\hline Kategori & \multicolumn{1}{c}{ Bobot } \\
\hline HC + Paint & $41.98 \%$ \\
\hline HO & $11.68 \%$ \\
\hline MO & $31.77 \%$ \\
\hline EO & $10.66 \%$ \\
\hline Acc & $3.92 \%$ \\
\hline Total & $100.00 \%$ \\
\hline
\end{tabular}

Pada kasus kedua (Tabel 2) yaitu pada Kapal Perintis 750 DWT didapatkan persentase bobot, yaitu hull construction (HC, termasuk paint) 41.98 persen, hull outfitting (HO) 11.68 persen, machinery outfitting (MO) 31.77 persen, electrical outfitting (EO) 10.66 persen, dan accomodation (Acc) 3.92 persen. Data yang diolah adalah penggabungan persentase bobot harga (ASSI, 2015; diolah) dengan data ekspor impor komponen yang didapatkan dari survey lapangan, serta diskusi dan informasi pendukung lainnya. Sehingga didapatkan bobot persentase TKDN pada komponen sebesar 54.61 persen, sedangkan sisanya adalah komponen impor sebesar 45.39 persen.

\section{Analisis Kemampuan Komponen Lokal}

Berdasarkan hasil identifikasi TKDN, didapatkan komponen apa saja yang masih impor. Komponen impor yang berpotensi untuk di produksi dalam negeri dianggap sebagai peningkatan TKDN. Maksud dari berpotensi adalah berteknologi sederhana dan sudah ada industri serupa di Indonesia. Tentunya dengan asumsi penerapan strategi product development dan market penetration, serta aliansi antar kompetitor. Misalnya pada penerapan strategi product development, industri yang sebelumnya hanya mampu membuat komponen land-use dapat membuat komponen marine-use ditahun 2019 atau aliansi antar kompetitor dengan kontribusi aset dan ketrampilan tertentu sehingga dapat memproduksi sebuah produk utuh. Market penetration dalam hal ini adalah pasar domestik, dengan maksud industri komponen mampu menguasai pasar domestik setelah berhasil mengembangkan produknya menjadi marine-use.

Tabel 3. Bobot peningkatan TKDN pada Kapal Tanker 17500 LDWT (PAL, 2012; PAL, 2015; diolah)

\begin{tabular}{lrrr}
\hline \multirow{2}{*}{ Kategori } & \multirow{2}{*}{ Bobot } & \multicolumn{2}{c}{ Bobot TKDN } \\
\cline { 3 - 4 } & & 2015 & 2019 \\
\hline HC + Paint & $29.91 \%$ & $22.18 \%$ & $29.91 \%$ \\
\hline HO & $25.12 \%$ & $11.30 \%$ & $16.85 \%$ \\
\hline MO & $29.50 \%$ & $0.70 \%$ & $2.72 \%$ \\
\hline EO & $10.12 \%$ & $0.61 \%$ & $5.62 \%$ \\
\hline Acc & $5.35 \%$ & $0.16 \%$ & $1.84 \%$ \\
\hline Total & $100.00 \%$ & $34.95 \%$ & $56.93 \%$ \\
\hline
\end{tabular}

Pada kasus pertama (Tabel 3) yaitu pada Kapal Tanker 17500 LDWT. Hasil peningkatan TKDN pada 2019 adalah hull construction (HC, termasuk paint) 29.91 persen, hull outfitting (HO) 16.85 persen, machinery outfitting (MO) 2.72 persen, electrical outfitting (EO) 5.62 persen, dan accomodation (Acc) 1.84 persen. Total peningkatan TKDN komponen adalah 21.98 persen dengan tingkat pangsa pasar domestik adalah hull construction (HC, termasuk paint) 100 persen, hull outfitting (HO) 67.07 persen, machinery outfitting (MO) 9.21 persen, electrical 
Analisis Peningkatan Kandungan Komponen Lokal pada Pembuatan Kapal Baru di Dalam Negeri ( Taufiq Hiayat dan Buana Ma'ruf )

Tabel 4. Bobot peningkatan TKDN pada kapal perintis 750 DWT (ASSI, 2015; PAL, 2015; diolah)

\begin{tabular}{|c|c|c|c|}
\hline \multirow{2}{*}{ Kategori } & \multirow{2}{*}{ Bobot } & \multicolumn{2}{|c|}{ Bobot TKDN } \\
\hline & & 2015 & 2019 \\
\hline $\mathrm{HC}+$ Paint & $41.98 \%$ & $41.98 \%$ & $41.98 \%$ \\
\hline $\mathrm{HO}$ & $11.68 \%$ & $9.89 \%$ & $10.91 \%$ \\
\hline MO & $31.77 \%$ & $0.00 \%$ & $0.75 \%$ \\
\hline EO & $10.66 \%$ & $0.79 \%$ & $7.25 \%$ \\
\hline Acc & $3.92 \%$ & $1.94 \%$ & $1.94 \%$ \\
\hline Total & $100.00 \%$ & $54.61 \%$ & $62.83 \%$ \\
\hline
\end{tabular}

outfitting (EO) 55.53 persen, dan accomodation (Acc) 34.30 persen.

Pada kasus kedua (Tabel 4) yaitu pada Kapal Perintis 750 DWT. Hasil peningkatan TKDN pada 2019 adalah hull construction (HC, termasuk paint) 41.98 persen, hull outfitting (HO) 10.91 persen, machinery outfitting (MO) 0.75 persen, electrical outfitting (EO) 7.25 persen, dan accomodation (Acc) 1.94 persen. Total peningkatan TKDN komponen adalah 8.22 persen karena TKDN awal sudah cukup tinggi, dengan tingkat pangsa pasar domestik adalah hull construction (HC, termasuk paint) 100 persen, hull outfitting (HO) 93.42 persen, machinery outfitting (MO) 2.37 persen, electrical outfitting (EO) 68,01 persen, dan accomodation (Acc) 49.55 persen.

\section{KESIMPULAN}

Dari hasil penelitian ini dapat disimpulkan sebagai berikut:

1) Dibutuhkannya strategi sebagai pendorong peningkatan kandungan komponen lokal pada pembuatan kapal baru, yaitu strategi product development dan market penetration.

2) Potensi peningkatan TKDN komponen pada Kapal Tanker 17500 LDWT adalah 21.98 persen, sedangkan pada Kapal Perintis 750 DWT adalah sebesar 8.22 persen.

3) Potensi peningkatan TKDN besarannya tidak sama untuk tipe kapal berbeda.

\section{DAFTAR PUSTAKA}

ASSI. (2015). Daftar Komponen Kapal Perintis 750 $D W T$, PT. Adiluhung Saranasegara Indonesia.

David, Fred R. (2013). Strategic Management Concepts and Cases, Prentice Hall.
Dussauge, P., dan Garrette, B. (1999). Cooperative Strategy, England: John Wiley \& Sons Ltd.

Hidayat dan Ma'ruf, B. (2015). Study of World-Leading Shipbuilding Industrial Cluster and Their Potential Application in Indonesia, Seminar Teori dan Teknologi Aplikasi Kelautan (SENTA) 2015.

Ma'ruf, B. (2014). Inovasi Teknologi untuk Mendukung Program Tol Laut dan Daya Saing Industri Kapal Nasional, Seminar Nasional Sains dan Teknologi Terapan II, 1-19.

Porter, M. E. (1998). Clusters and the New Economics of Competition, Harvard Business Review, Vol. 76 Issue 6, p77.

PAL. (2012). Daftar Komponen Kapal 17.500 LTDW Oil Tanker, PT. PAL Indonesia.

PAL. (2015). Daftar Ekspor-Impor Komponen Kapal, PT. PAL Indonesia.

Wee, V. (2013). Indonesian Shipbuilding Industry Unlikely to Meet Targets, Retrieved July 3, 2015 from http://www.seatrade-maritime.com/news/ asia/indonesian-shipbuilding-industry-unlikely-to -meet-targets.html. 
Jurnal Wave Volume 10 Nomor 2, Desember 2016; Hal 61-66

\section{[ Halaman Kosong ]}

